\title{
Effects of fat-containing feed after ultrasound treatment with zeolite on the metabolism
}

\author{
Artem Bykov ${ }^{1 *}$, Larisa Mezhueva $^{1}$, Khamdiya Dusaeva ${ }^{1}$, Tat'yana Krakmaleva ${ }^{1}$, and El'vira \\ Maneeva $^{1}$ \\ ${ }^{1}$ Orenburg State University, prospekt Pobedy, 13, Orenburg, 460018, Russia
}

\begin{abstract}
Processing technologies using non-reactive influences appear to be the most profitable in terms of safety and ecological compatibility of end products including fodder for the agro-industrial complex. The usage of various physical influences allows significantly speeding up and facilitating technological processes including those achieving results that are not possible with other technologies. Based on the study of morphological and biochemical indicators of blood, it can be stated that the introduction of cavitationally processed sunflower sludge into the diet of birds together with zeolite powder leads to improving general blood indicators. All biochemical and morphological indicators were within the physiological norm. The results indicate that the cavitational processing of sunflower sludge with zeolite particles comprising feed mixes with an additional increase in the level of metabolizable energy leads to an increase in the content of macroand microelements against the background of a significant reduction of elements-antagonists. The greatest changes were observed in the second experimental group, (a diet with a metabolizable energy content of 14.9 $\mathrm{MJ} / \mathrm{kg}$ of dry matter (DM), which consists of $6 \%$ of cavitationally processed sunflower sludge in the presence of zeolite in the amount of $4 \%$ ).
\end{abstract}

\section{Introduction}

In terms of a number of attributes, the development level of a society can be largely characterized by the efficiency of using waste products. In this regard, advanced societies are distinguished by the combination of high-tech industries and minimal environmental impact. The efficient use of production waste is one of the major problems in our country. In addition, besides the Pan-European standard which serves as a reference sample for our society, it is necessary to understand the fact that only waste-free production can become the basis for the effective economy. Sunflower sludge is of particular interest to the domestic animal husbandry. This waste is a good source of valuable protein, since it is inferior to animal protein only in the content of lysine. The only drawback of such feeds, and particularly of sunflower one, is the significant content of crude fiber due to husk [1].

One should understand that general term "sunflower sludge" implies two types of waste resulting from two different processes of oil production. Within the process of filtering the pressed oil, impurities (millcake particles, seed shells, etc.) are deposited on the filter press

\footnotetext{
${ }^{*}$ Corresponding author: artem19782@yandex.ru
} 
sheets and removed during cleaning, including particles from cleaning all presses, oil pipelines, floors of press sections, etc. This waste product is a thick, brownish-gray mass containing up to $40-65 \%$ of substances extracted with ether [2].

Processing technologies using non-reactive influences appear to be the most profitable in terms of safety and ecological compatibility of end products including fodder for the agroindustrial complex. The usage of various physical influences allows significantly speeding up and facilitating technological processes including those achieving results that are not possible with other technologies [3].

Cavitation is a type of acoustic processing methods of products including feed. In this process, there is the formation of pulsating bubbles (so-called caverns or cavities) at a certain intensity of sound in the liquid. The bubbles are filled with steam, gas, or mixture [4].

Sunflower sludge is of particular interest for domestic livestock. These wastes are good sources of valuable protein that is inferior to animal protein only in the lysine content.

\section{Materials and methods}

In the course of the pilot studies, there was determined digestibility of dry matter of cavitationally processed products. It was also discovered that this indicator depends on the humidity of the raw materials and its gravimetric composition.

In order to optimize the process of ultrasonic processing of sunflower sludge, there were carried out studies on the effect of the addition of zeolite powder of dispersity with an equivalent diameter of no more than $1.5 \mathrm{~mm}$ on the performance of the ultrasound device, and also on the quality of ready-made feed products.

In order to implement the proposed technology and obtain a new product, a variant of the machine-hardware scheme was proposed. The scheme is supposed to use a cavitator for processing sunflower sludge and zeolite microparticles. The cavitator has a body made in the form of a cylinder, and the working organ of it is a pentagonal star-shaped pyramid - the emitter of ultrasound - the piezoceramic element.

The technological scheme of processing sunflower sludge on feed envisages an operation of two-fold ultrasound treatment. The first exposure is done when sunflower sludge gets mixed with water and the second one - when particles of zeolite get added to the prepared product.

Sunflower sludge watered to the humidity of $55 \%$ was taken for cavitational processing. This level of humidity was chosen as the maximal performance of the ultrasound device for this type of product was observed at this exact humidity.

To confirm the effectiveness of the stated processing method, our experiments were conducted on the broiler chickens of the "Smena-7" cross. Feeding the birds was carried out with feeds manufactured on the recommendations of the Federal Scientific Center "AllRussian Research and Technological Poultry Institute” (FSC “ARRTPI”) (2004). During the experiment, broiler chickens up to 4 weeks of age received a starting composition and then a growth one.

\section{Results and discussion}

\subsection{Morphological and biochemical blood indicators}

Any experiments involve a great physiological burden on the bird's body. The slightest error in the preparation of feed mixtures or feeding technology can cause irreversible shifts in the metabolism of the bird leading to alimentary diseases. One way to detect these disorders is to intravitally diagnose metabolic disorders with the help of morphological and biochemical 
blood indicators. These studies are particularly important in assessing the effects of new fodder substances[5-7].

Assessing the effects of cavitationally processed sunflower sludge together with zeolite powder on the bird's body revealed the following morphological indicators of blood.

Morphological indicators of the blood of the experimental birds during the experiment were within the physiological norm. It should be noted that the highest level of hemoglobin was in the III experimental group and exceeded the same rate by $10.5 \%$ in the control group, by $8.9 \%$ in the I experimental group, and by $1.1 \%$ in the II experimental group. The maximum content of leukocytes was also recorded in the III experimental group and made a difference of $14.6 \%$ with the control, of $4.2 \%$ - with the first experimental group, and of $4.5 \%$ - with the II experimental group.

The analysis of the leukocyte formula and its indicators in all experimental groups were within the physiological norm. The concentration of lymphocytes ranged from 63.1 to 64.9 $\%$, which indicates that there were no inflammatory processes in the experimental bird. Indicators of the number of basophils and eosinophils state the fact that there was no allergic reaction to the introduction of studied feed additives and parasitic diseases.

Based on the obtained data, it can be stated that the introduction of sunflower sludge into feed after cavitational processing combined with zeolite powder does not have pronounced changes in the morphological composition of the blood in the experimental groups.

At the same time, the main biochemical indicators of blood were determined in the study of the effectiveness of the additives.

Based on the obtained data, it can be concluded that the total protein content in the III experimental group was higher than that in the control group by $2.9 \%$, in the first experimental group - by $1.7 \%$, and in the II experimental group - by $0.2 \%$.

The amount of urea is determined by the difference between the amount of nitrogen received from food and the amount of nitrogen in excreted compounds. Urea excretion reduces if the nitrogen balance is positive. If there occurs an increase in nitrogen excretion due to the breakdown of the body's proteins, the increase in nitrogen in the serum emerges due to urea. Thus, urea formation is a regulatory mechanism which nitrogen equilibrium is maintained by. Based on the biochemical analysis of experimental birds' blood, it can be concluded that the introduction of cavitationally processed sunflower sludge together with zeolite into the diet leads to a reduction in the amount of urea in the serum by two times compared to the control.

The creatinine content also had a decrease after the introduction of the studied feed additives. Thus, the content of creatinine in the control group was $66.4 \mathrm{Mmol} / \mathrm{l}$. At the same time, the difference of this indicator with the control was $8.5 \%$ for the first experimental group, $16.9 \%$ for the second group, and $21.2 \%$ for the third one.

\subsection{Assessment of the effect of different dosages of zeolite powder on mineral metabolism in broiler chickens}

Metabolic processes are ensured by all systems of a living organism. Due to this process, a body is supplied with building and energy materials and discharges metabolic products that are useless or harmful for it. As a result of the processes of assimilation and dissimilation, the substances received in the body are processed. Birds are notable for numbers of metabolic features. In particular, bird's energy metabolism is 1.5-2.0 times higher than mammals'. The introduction of zeolite powder during the processing of a fat-containing additive has influenced the energy balance in the body of the bird under research.

Based on the studies, the following conclusion can be drawn up: the introduction of a cavitation-treated sunflower sludge together with zeolite powder into the bird's diet entails energy losses with metabolic products, while the index of efficiency of using exchange 
energy increases, and the correspondence coefficient indicates an increase in the energy efficiency for building new tissues.

Changes in the level of metabolizable energy of the diet affected the mineral content in the body of the experimental birds [8].

Table 1. Changes in the level of metabolizable energy of the diet

\begin{tabular}{|c|c|}
\hline \multirow{2}{*}{ Type of elements } & $\underline{\text { Changes }}$ \\
\hline - essential and conditionally essential \\
microelements & $\underline{\mathrm{As}, \mathrm{Cr}, \mathrm{Cu}, \mathrm{Fe}, \mathrm{I} \uparrow}$ \\
\cline { 2 - 2 } - macroelements & $\mathrm{Co}, \mathrm{Ni}, \mathrm{Se} \downarrow$ \\
\cline { 2 - 2 } & $\underline{\mathrm{Ca}, \mathrm{Na} \uparrow}$ \\
\hline \multirow{2}{*}{ - toxic elements } & $\underline{\mathrm{Al}, \mathrm{Cd} \uparrow}$ \\
\hline
\end{tabular}

We found that increasing the level of metabolizable energy resulted in a slower accumulation of $\mathrm{Co}, \mathrm{Ni}, \mathrm{Se}, \mathrm{Ca}, \mathrm{P}, \mathrm{Pb}, \mathrm{Sr}$ in the tissues of the body of a bird against the background of an increase of $\mathrm{As}, \mathrm{Cr}, \mathrm{Cu}, \mathrm{Fe}, \mathrm{I}, \mathrm{K}, \mathrm{Na}, \mathrm{Al}, \mathrm{Cd}$, which were within the norm [9].

To confirm the safety of products, a micronutrient analysis of muscle tissue (meat) of experimental animals was carried out.

\section{Conclusion}

Based on the study of morphological and biochemical indicators of blood, it can be stated that the introduction of cavitationally processed sunflower sludge together with zeolite powder into the diet of birds leads to the improvement of basic blood indicators. All biochemical and morphological indicators were within the physiological norm [10].

So, the obtained results indicate that cavitational processing of sunflower sludge in combination with zeolite particles that make up feed mix with an additional increase in the level of metabolic energy leads to an increase in the macro- and microelement content against the background of a significant reduction of antagonist elements. And the greatest changes were observed in the second experimental group, which received a ration with the metabolizable energy content of $14.9 \mathrm{MJ} / \mathrm{kg}$ of dry matter $(6 \%$ of cavitationally processed sunflower sludge in the presence of zeolite in the amount of $4 \%$ ).

\section{Acknowledgement}

The research was carried out in accordance with the plan of research works of the Federal research center Biological systems and agrotechnologies of the Russian Academy of Sciences (no. 0761-20190005)

\section{References}

1. A.N. Sizentsov; O.V. Kvan; A.I. Vishnyakov; A.E. Babushkina; E.A. Drozdova. Life science journal, 11, 18-20, (2014).

2. S. Miroshnikov; A. Kharlamov; O. Zavyalov; A. Frolov; I. Bolodurina; O. Arapova; G. Duskaev, Pakistan Journal of Nutrition, 14, 632-636, (2015). http://dx.doi.org/10.3923/pjn.2015.632.636. 
3. A.N. Sizentsov; O.V. Kvan; E.P. Miroshnikova; I.A. Gavrish; A.V. Bykov; V.A. Serdaeva. Environmental Science and Pollution Research 25, 15765-15773, (2018). https://doi.org/10.1007/s11356-018-1761-4.

4. V. Kalashnikov; A. Zajcev; M. Atroshchenko; S. Miroshnikov; A. Frolov; O. Zavyalov; L. Kalinkova; T. Kalashnikova Environmental Science and Pollution Research, 25, 21961-21967, (2018). https://doi.org/10.1007/s11356-018-2334-2.

5. S.A. Peshkov; A.N. Sizentsov; H.N. Nikiyan; G.I. Kobzev Modern problems of science and education, 4, 1-7, (2017).

6. A. Sizentsov; G. Karpova; T. Klimova; E. Salnikova; O. Kvan; E. Barysheva; I Gavrish, International Journal of GEOMATE, $16 \quad$ (55), 8-13, (2019). DOI: $10.21660 / 2019.55 .76923$

7. J. K. Wisch; E. Farrell; M. Siegel; S. Freyermuth. Biochem Mol Biol Educ, 46(6):602611,(2018). doi: 10.1002/bmb.21176.

8. L. Moro; G. Pezzotti; M. Turemis et al., Mar Pollut Bull, 129(1), 212-221, (2018). doi: 10.1016/j.marpolbul.2018.02.036.

9. F. Boriani; N. Fazio; F. Bolognesi et al. World Neurosurg, 18, 32502-32506, (2018). doi: 10.1016/j.wneu.2018.10.195.

10. O. Kvan, G. Duskaev, Sh. Rakhmatullin D. Kosyan International Journal of Environmental Science and Development. 10 (12), 419-423 (2019). DOI: $\underline{10.18178 / \text { ijesd.2019.10.12.1209 }}$ 